\title{
Racismo e Antirracismo: multiculturalismo e transversalidade na Educação da
}

\section{América Latina}

\author{
Racism and Anti-racism: multiculturalism and transversality in Latin American Education
}

Racismo y Antirracismo: multiculturalismo y transversalidad en la Educación de América Latina

Recebido: 20/08/2021 | Revisado: 25/08/2021 | Aceito: 27/08/2021 | Publicado: 30/08/2021

\author{
Antonio Gomes da Costa Neto \\ ORCID: https://orcid.org/0000-0002-9614-920X \\ Secretaria de Estado de Educação do Distrito Federal, Brasil \\ Universidade de Brasília, Brasil \\ correio.antonio@gmail.com
}

\begin{abstract}
Resumo
O artigo aborda a educação e a consecução das políticas antirracistas como capazes de identificar o valor arbitrário cultural do modelo de imposição e inculcação pela educação, consoante políticas públicas de combate ao racismo. A metodologia utilizada é a revisão da literatura sobre as políticas antirracistas na Educação, quando observado o contexto da América Latina, utilizando-se dos paradigmas da adoção do multiculturalismo e da transversalidade. Para tanto apresenta a recepção das políticas multiculturalistas na região, bem como essas são acolhidas perante os sistemas de ensino da América Latina. Apresenta também a proposta da sua consecução e consolidação do modelo da diversidade; oportunidade em que os diversos governos da região adotaram as políticas de transversalidade. Dessa forma as políticas públicas antirracistas, ao defenderem a proposta de inclusão, no ciclo das políticas, por meio do multiculturalismo pela transversalidade é a razão pela qual os órgãos de avaliação não conseguem demonstrar como essa integração proporcionaria a melhoria dos critérios de avaliação do Estado. Portanto não produz eficácia social.
\end{abstract}

Palavras-chave: Antirracismo; Políticas; Eficácia social.

\begin{abstract}
The article approaches education and the achievement of anti-racist policies as capable of identifying the arbitrary cultural value of the model of imposition and inculcation by education, according to public policies to combat racism. The methodology used is a literature review on anti-racist policies in Education, when observing the context of Latin America, using the paradigms of adopting multiculturalism and transversality. Therefore, it presents the reception of multiculturalist policies in the region, as well as how these are welcomed by the education systems of Latin America. It presents the proposal for its achievement and consolidation of the diversity model; opportunity in which the various governments in the region adopted transversality policies. In this way these anti-racist public policies, in defending the proposal of inclusion, in the policy cycle, by multiculturalism through transversality, is the reason why the assessment agencies are unable to demonstrate how this integration would improve the State's assessment criteria. Therefore, it does not produce social effectiveness.
\end{abstract}

Keywords: Anti-racism; Policies; Social effectiveness.

\section{Resumen}

El artículo aborda la educación y la consecución de las políticas antirracistas como capaces de identificar el valor arbitrario cultural del modelo de imposición e inculcación por la educación, en conformidad con las políticas públicas de combate al racismo. La metodología utilizada es la revisión de la literatura sobre las políticas antirracistas en Educación, al observar el contexto de América Latina, sirviéndose de los paradigmas de adopción de la multiculturalidad y transversalidad. Para ese propósito, presenta a la recepción de las políticas del multiculturalismo en la región, así como esas son acogidas frente a los sistemas de enseñanza de América Latina. Presenta también la propuesta de su consecución y consolidación del modelo de la diversidad; oportunidad en la que los diversos gobiernos de la región adoptaron las políticas de transversalidad. Así, las políticas públicas antirracistas, en la defensa de la propuesta de inclusión, en el ciclo de políticas, por intermedio del multiculturalismo por la transversalidad es la razón por la cual los órganos de evaluación no logran demostrar cómo esa integración proporcionaría la mejora de los criterios de evaluación del Estado. Por tanto no produce eficacia social.

Palabras clave: Antirracismo; Políticas; Eficacia social. 


\section{Introdução}

Hodiernamente, discorrer sobre a efetividade das políticas de combate ao racismo na Educação na América Latina remete-nos aos antecedentes e processos históricos do tratamento destinado aos povos originários, bem como àqueles trazidos forçosamente. Ademais, ao modelo de inclusão no sistema internacional de direitos e sua recepção na Educação (Costa Neto, 2016, 2019).

De acordo com Foucault (2010), essa institucionalização opera-se pelo discurso científico, quando "toma corpo numa universidade ou, de um modo geral, num aparelho pedagógico" (idem, p. 10). Portanto, o racismo e o antirracismo estão inseridos no Poder do Estado pelo direito, poder e verdade.

Entretanto, o poder só funciona se submetido à produção de uma verdade, ou seja, "somos forçados a produzir a verdade pelo poder que exige essa verdade, e que necessita dela para funcionar" (Foucault, 2010, p. 22). Logo, o ideal de modelo da vida cristã desde a Idade Média (Le Goff, 2006), cujo poder régio fixava e legitimava a obrigação legal da obediência pela dominação.

Segundo Guimarães (2009), no campo de pesquisa científica, a inclusão de uma perspectiva antirracista tem relação com a definição de "raça"; inicialmente, pela atribuição de sua origem comum, passando por teorias biológicas e por distinções. Isso tanto físicas como de capacidade mental. Fenômeno esse ocorrido até o final da Segunda Guerra, quando da tragédia ocorrida naquele período.

De acordo com Cashmore (2000), o uso do grafema "raça" advém do século XVI, e tem sido utilizado com o propósito de se referir às características comuns em razão da mesma ascendência. Eis que durante o decorrer do século XVIII, tinha como paradigma para sua explicação o Antigo Testamento, pela seguinte razão: “como um designío de Deus, como resultado das diversidades ambientais, independentes de questões morais, e como fruto de diferentes ancestrais originais" (Cashmore, 2000, p. 448).

Com o início do século XIX, atribui-lhe vários outros sentidos, entre eles o de tipo que designava seres humanos distintos, em razão da existência de constituição física semelhante, bem como em função da capacidade mental, permeando como essência que se configurou e foi designado como "racismo científico" (Cashmore, 2000; Guimaraes, 2009).

Contudo, "raça", quando relacionado ao discurso, i.e., como significante, é utilizado como "expressão, som ou imagem, cujos significados são viabilizados somente por meio da aplicação de regras e códigos” (Cashmore, 2000, p. 451). Logo, sua inserção na educação e sua decodificação somente se operam nos parâmetros do discurso, eis que a língua é um meio do processo de racialização.

No que tange à educação das relações étnico-raciais, cujo sentido é de produzir material para uma prática antirracista, como ressalta a crítica de Young (2005), em relação à teorização sobre as diferenças atribuídas entre as raças, ninguém se preocupava muito "antes de se tornar vantajoso para o ocidente. Em termos econômicos, significa lucrar com a escravidão ou defendê-la contra os abolicionistas" (idem, p. 112).

Situação inserida no campo de poder e na estrutura da distribuição do capital, quando "destinado a conservar ou transformar o campo de força de um outro socialmente construído, onde se afrontam agentes dotados de recursos diferentes" (Bourdieu, 2005, p. 33), os quais são revelados por implicações semânticas, que integram o campo e a "lógica específica da instituição escolar" (Bourdieu, 2008b, p. 35), bem como sua complexa interação com as práticas sociais (Costa Neto, 2012, 2015, 2016, 2017, 2019a, 2019b; 2021a, 2021b; Rodrigues, 2021; Van Dijk, 2012, 2021).

Discorrer sobre a educação e suas conexões constitui o propósito deste trabalho, no sentido de conseguir observar se a consecução das políticas antirracistas é capaz de identificar o valor arbitrário cultural do modelo de imposição e inculcação pela educação. Esta, quando se manifesta pela desvalorização implícita ou explícita das demais. Isso consoante políticas públicas de combate ao racismo. 


\section{Metodologia}

O presente trabalho constitui uma revisão da literatura para a análise das políticas antirracistas na Educação, quando observado o contexto da América Latina, utilizando-se dos paradigmas de análise da adoção do multiculturalismo e da transversalidade.

Para alcançar o propósito adotamos a pesquisa de cunho qualitativa, por meio da técnica de levantamento de dados e revisão da literatura, de modo a propiciar o vasto conhecimento sobre o tema com o objetivo de demonstrar os significados dos eventos da vida real; não apenas as ocorrências (Yin, 2016)

Por sua vez, no tocante ao levantamento documental, para uma melhor observação do contexto social dos diferentes interesses políticos, portanto, compreender as políticas de combate ao racismo em contextos educacionais (Bodgan \& Biklen, 2006; Costa Neto, 2019, 2020; Gundara, 2012; Van Dijk, 1993, 1998, 2000, 2003, 2012, 2012B; Watkins, 2010).

\section{Referencial teórico}

\subsection{Notas sobre o conceito do racismo}

Young (idem) assevera que, para a questão do racismo, há outro ponto de extrema relevância ao se discutir - o "racismo moderno foi uma invenção acadêmica" (idem, p. 79). Isso pela ótica da fisiologia e linguagem. O objetivo desse saber racial foi no sentido de projetar uma pretensão universitária, quando de sua relação com a raça, que penetrou de tal forma no inconsciente que, desconstruí-la, constitui-se em árdua tarefa.

Todorov (1982), historicamente, atribui a viagem de Colombo (1492) ao Caribe, no momento da "descoberta" da América, Desse encontro com os povos originários - indígenas - atribuíram-lhes como desprovidos de qualquer propriedade cultural, identificados como portadores de línguas e costumes não compreendidos, "gente sem razão" (Wolf, 1982), "sem religião, sem justiça e sem estado" (Fausto, 2005, p. 11), atribuiram-lhes a barbárie em contraponto a civilização ao argumento da superioridade modernizante em contraste ao atraso, argumentava essas características em face da construção filosófica do colonizador (Vanucchi, 1999).

Por essa razão revelam a principal motivação dessa empreitada - o desejo de enriquecer pela procura do ouro em favor dele, dos marinheiros e dos Reis da Espanha. Objetivavam-se a conquista material (riqueza) e a expansão espiritual (cristianismo), em razão dos ideais da civilização espanhola voltada para a riqueza, poder, justiça ou de santidade (Ribeiro, 1983; Todorov, 1982).

Segundo Woortmann (2000), trata-se da construção filosófica presente na história dos povos ibéricos, imposta aos povos conquistados, como filosofia política e mecanismo de sustentação. Isso durante todo o processo de colonização, com efeitos até os dias atuais (Fausto, 2005), cujo sentido é produzir um discurso de "forma aproximativa e imperfeita, que a verdade assume; usualmente unida a uma validade moral ou religiosa" (Dupas, 2006, p. 22).

De acordo com Maldonado-Torres (2007), o sistema de dominação criado no contexto do colonialismo da Europa, nas Américas, em que as formas múltiplas de subalternização (raça) e a desumanização foram as práticas adotadas em toda a região. Conforme Grosfoguel (2012, 2016), é por intermédio de Colombo que surge o racismo religioso, considerado "la primera forma de racismo en "el sistema-mundo capitalista/patriarcal occidental-céntrico/cristiano-céntrico moderno-colonial"” (GrosfogueL, 2012, p. 90).

Essa argumentação se sustenta na seguinte lógica: "se você não tem uma religião, você não tem Deus; se você não tem um Deus, você não tem alma; e, por fim, se você não tem alma, não é humano, mas animal" (GrosfogueL, 2016, p. 37). Porém, para estabelecer-se de forma perene, agregou-se o "mito da pureza de sangue" (Carneiro, 2005; Figuerôa, 2009; Grosfoguel 2012, 2016). 
De acordo com Carneiro (2005), o "mito da pureza de sangue" tem sua origem nas divergências religiosas entre cristãos e infiéis, quando da edição do Estatuto-Sentença de Toledo (1449), cujos critérios de mensuração foram pautados por um sistema legal, simbólico, teológico e social, dividindo em dois grupos: os limpos e os infectos de sangue (Bonfim, 2014; Franco, 2011; Lima, 2011; Rodrigues, 2012; Sicroff, 1982). Conforme Carneiro (2005, pp. 36-37) a causa fundante foi o seguinte fato:

A causa incidental dessa revolta foi a imposição de uma pesada taxa de imposto, perto de um milhão de 'maravadis' arrecadadas por Álvaro de Luna, favorito de D. João II, para financiar a campanha de Aragão. Incitado por Pedro Sarmiento, comandante do burgo de Alcazar de nomeado real, e por um artesão ignorado, o povo indignado com o tributo - atribuiu a Alonso Costa, um rico comerciante converso, a suspeita de ter sido o instigador de tal cobrança. A rebelião teve início quando foi ateado fogo à casa de Alonso Costa, então cobrador de impostos. Em nome do rei, foi saqueado o quarteirão de Madalena, habitado por ricos conversos e foram sequestrados os bens dos negociantes cristãos-novos.

Sarmiento, com o poder da administração municipal nas mãos, ordenou a prisão do líder cristão-novo e, após o inquérito religioso-judicial, sentenciou-o a ser queimado. No decorrer desses acontecimentos, surge o primeiro Estatuto de Pureza de Sangue quando Sarmiento, Senhor de Toledo, proclamou a Sentencia Estatuto, diante de uma assembleia popular, com o apoio de homens letrados. Esse acontecimento, de 5 de junho de junho de 1449, é conhecido como Ajuntamento de Toledo.

Os detentores do sangue infectado eram os judeus, negros, indígenas, ciganos ou mouros, os quais eram usados como instrumento de preservação social no antigo regime - legislação discriminatória, segregacionista racial e social, inicialmente, imposta aos cristãos-novos e aplicado pela Espanha e Portugal (Carneiro, 2005; Souza, 2008).

Cuida-se de uma legislação e política racista antissemita. Há registro, na Espanha, de instalação de um Tribunal de Inquisição (1478), resultando na expulsão de judeus do reino em 1492. O destino desses foi Portugal; contudo, desaparece na legislação portuguesa em 1774 por decreto de Pombal. Isso tão somente em relação à discriminação legal contra o judeu, o mouro e o cristão-novo, permanecendo em relação aos negros (Lima, 2011; Figuerôa Rego, 2009).

Porém, sistema utilizado desde 1536, na América Espanhola (Carneiro, 2005; Olival, 2004; Franco, 2011). De igual sorte, nas instituições militares, nas ordens religiosas, no sistema educativo da educação superior em Portugal e Espanha, desde o século XVI, até os anos da abolição (Carneiro, 2005; Figuerôa Rego, 2009; Grinberg \& Peabody, 2013; Mintz, 1996; Pinsk, 2009).

Conforme com Grinberg e Peabody (2013) os mecanismos legais da sustentação da escravidão na América Espanhola podem ser identificados desde o direito romano na obra Las siete partidas, empregadas de 1493 a 1866; e, por influência direito escravista do Code Noir da França houve tentativas de regulamentação no Código de Santo Domingo (1768), de Lousiana (1769) e Carolino (1784), cujos objetivos eram o de controlar a vida dos escravos e não dos negros em geral, porém, aplicado em algumas regiões (Salmoral, 1999).

O tratamento homogêneo a todos os escravos da América Espanhola se deu pela Instrucción sobre educacion, trato y ocupación de los esclavos (1789), do qual foi um a tentativa de sustentar e prolongar a escravidão, todavia, as guerras de independências na maior parte das colônias deram o início ao processo de fim da escravidão nas terras dominadas pelos espanhóis.

Em relação à América Portuguesa, a sustentação legal da escravidão estava regulada até a década da independência do Brasil em 1820, inicialmente, nas Ordenações Manuelinas (1521), e pelas Ordenações Filipinas a partir de 1603 até sua revogação pelo Código Civil de 1917 e com a abolição da escravidão no Brasil em 1888 (Grinberg \& Peabody, 2013).

Trata-se de uma das épocas mais dramáticas e torturantes da história humana - período marcado pela escravidão moderna (Moura, 2004), a qual foi considerada como "marco econômico, político e militar" (Mintz, 1996, p. 380). E a partir da inserção no capitalismo, bem como a sua expansão e consolidação na América Latina. Segundo Elliot (1990) e Silva (1990), 
sustentada por meio de diversas bulas papais vigentes até o Tratado de Madrid (1750).

Conforme Descher (2011), até o século XVIII, a escravizibilidade foi um fenômeno apoiado em visões religiosas, pela ordem legal, tradições patriarcais, proféticas e legisladores da "raça humana", aplicada na América Espanhola e Portuguesa, de forma perene, de 1450 a 1789 - Portugal, bem como Espanha, e as demais nações europeias a praticavam: França (Code Noir e police des noirs); Grã-Bretanha (Constituição da Carolina); Países Baixos (VOC - Vereenigd Oost-Indische Compagnie e WIC - West-Indische Compagnie), em razão das políticas comerciais comércio -, i.e. tratava-se de ordem legal, institucional, econômica e evangelizadora (Barnadas, 1990; Patterson, 2008; Ribeiro, 1983).

O que distingui a parte Ibérica do restante da Europa era a sua legislação escravista, empregada na América e lastreada nos códigos escravistas romanos e Justiniano. Com isso, estabeleceram-se os "limites legais e morais gerais à instituição, bem como estipularam procedimentos legais para a saída da escravidão" (Drescher, 2011, p. 16).

Houve diversas tentativas, por parte dos descendentes de africanos, de pôr fim a essa forma de submissão. Todavia, foi objeto de repressão por parte das monarquias escravistas, nas colônias, consoante correntes antiescravistas. Em geral, marcada por revoltas, guerras e o exercício do contrapoder. Porém, como ato das metrópoles colonizadoras, a escravidão foi "eliminada por atos abolicionistas formais, datados e legalizados" (Gorender, 1990, p. 134).

A escravidão, de acordo com Gorender (2000), extinguiu-se nas Américas, e não o racismo. Não se contava com uma segregação racial definida por lei, mas sim, pela inserção de ideais liberais e positivistas, influenciados pela filosofia clássica, a qual assumiu o paradigma do conhecimento científico, cujos reflexos atingiram a construção da identidade nacional e de uma sociedade industrial (Machado, 2012; Holanda, 1936; Mariátegui, 1928; Morse, 2000, Hurtado, 2008).

A nova visão representava a mudança da realidade da região, buscando-se tentar romper com o pensamento colonial, inserindo um novo princípio de liberdade, com a inclusão de conceitos como Civilização e Progresso, cujo manejo político pelas oligarquias caracterizou-se pela submissão à Europa e à América do Norte (Hernandez, s.d.; Souza, 2012).

Porém, a origem africana, como variável constante na história do continente latino-americano, o qual recriou suas formas sociais e culturais, em que teorias raciais sustentadas em hierarquias (biológica, diferenças e subalternidades), teorias evolucionistas, sociais darwinistas influenciram a produção científica, cultural e artística (Machado, 2012).

Do mesmo modo, a inserção de correntes científicas como a poligenia, a partir de conceitos de diferenças culturais e raciais (Young, 2005), apesar do seu declínio no final do século XIX, e o evolucionismo poligenista a partir do darwinismo, foram a "base cientificamente legitimada para a manutenção da supremacia branca" (Glick, 2003, p. 23).

Recepcionada pelas "teorias sociais, jurídicas e políticas, como na literatura" (Gualtieri, 2003), além da denominada Eugenia Moderna, considerada a "representação do ideal de melhoria da raça para se atingir a pureza racial" (Diwan, 2007, p. 21) e nas teorias do branqueamento (Hasembalg, 2005; Hofbauer, 2006; Nobles, 2009).

Portanto, a questão da raça como "fenômeno histórico produzido por meio de discursos é que tem variado no tempo e no espaço" (Machado, 2012, p. 33). Consequentemente, sua reprodução nos sistemas de ensino é recorrente, como instrumento de consolidação e de construção do racismo, além de "ferramenta ideológica para justificar a hierarquização" (Machado, idem, p. 33).

Dessa maneira, o colonialismo foi "constitutivo do próprio processo de formação das nações” (Machado, 2012, p. 42), estabelecendo-se o domínio colonial. E "raça" se transformou em ferramenta histórica, que influenciou as repúblicas com explicações de resultados de "formações biológicas e físicas" (Machado, ibidem, p. 34), em que a identidade, cultura, raça perduraram historicamente e adquiriram novos modelos.

Conforme Moura (2004), com a escravidão moderna ou colonial, para manter-se como estrutura, sempre esteve lastreada por questões religiosas, jurídicas e pela ciência. Isso se deu de forma violenta, em qualquer local que tenha existido, até a sua abolição, a qual a transformou colônias em nações independentes, constituindo novos dilemas pela diversidade social, 
econômica, regional, racial e cultural (Ianni, 1988, p. 5).

Quando os conquistadores tornam-se nativos, surgem as incoerências, revoluções e revoltas na formação da história do território de seu povo. Do mesmo modo, há divergências internas e conflitos. Ademais, o jogo de forças não absorvidos gera controvérsias para a consolidação dos estados nacionalistas em diversas partes da América Latina (Bambirra, 1988; Cotler, 1988; Ianni, Idem; Cuello, 1988). Portanto, o discurso legitimador institucional racista, expresso por ações formais e informais, por vezes, constituem atos socialmente aceitáveis e oficiais (Van Dijk, 2006).

Por essa razão, ao se identificar o preconceito, que pertence ao campo das ideias, dos processos mentais, podendo ser constatado no discurso (escrito e oral), que depende de um conceito sociopsicológico, que tanto acentua sentimentos, atitudes e a primazia do grupo (Jones, 1973; Van Dijk, 2012), assim como a discriminação que, no sistema escolar, produz o racismo individual, institucional e cultural, no qual o primeiro pode ser considerado o "mais próximo do preconceito racial". Isso quando propõe uma “crença na superioridade de nossa raça com relação à outra” (Jones, ibidem, p. 4).

O segundo é representado pela "manipulação consciente de instituições, a fim de atingir objetivos racistas" (Jones, ibidem, p. 5). Esse fenômeno pode ser manifesto ou oculto, respectivamente de jure ou de facto, i.e., as "práticas, as leis e os costumes estabelecidos que, sistematicamente, refletem e provocam desigualdades raciais” (Jones, ibidem, p. 117) de caráter muito difuso na sociedade (Cashmore \& Jennigs, 2001; Jones, 1972; Pala, 2010; Pilkington, 2008; Wieviorka, 2007; Stokely \& Hamilton 1967), posto isso a seguinte definição:

Característica do indivíduo que se esforça para persuadir sua identificação, porém, consiste em atos intencionais praticados sob a égide de um mecanismo organizado, normalmente ao abrigo da forma institucionalizada, instaurado na certeza de está permeado de aquiescência dos grupos dominantes, propagado dentro de ambientes organizacionais resguardados pela regra do poder burocrático dentro do poder institucionalizado.

Para consolidar-se faz uso de uma ação espontânea, continuada e prolongada da destruição física, emocional e intelectual dos coletivos da sociedade, para se efetivar utiliza da omissão, subordinação, cooptação e a deliberada vontade de não alterar quaisquer das situações evidenciadas em desfavor da sociedade, dessa forma tolhe os direitos morais e materiais de todos aqueles que estão fora das esferas de poder de alcançar algum benefício coletivo.

Esse poder, habitualmente vinculado à seara do poder institucionalizado se exerce pela ação - ato individual - por ação ou omissão, sem recalcitrância, com pleno conhecimento dos resultados em face da subordinação formal e do voluntário ato de manter-se cooptado, por vezes argumenta ter exaurido os espaços dentro do campo do poder, todavia, não admite ou assume o ônus de haver contribuído para a manutenção e perpetuação dos danos, por essa razão julgam-se isentos da condenação, por vezes avultado por recompensas burocráticas e patrimoniais (Costa Neto, 2020).

Dessa maneira, o racismo institucional, quando atua nas "operações anônimas de discriminação em organizações, profissões, ou até mesmo sobre sociedades inteiras" (Cashmore, 2000, p. 469), utiliza-se dessa forma de agir para evitar a responsabilização ao argumento da ausência de atores sociais (Wieviorka, 2007).

Bemo como pela observação do racismo cultural, ao reconhecer que esse "contém elementos do racismo individual e institucional" (Jones, 1972, p. 5), o qual é considerado o "rótulo adequado para o ato de exigir que tais minorias culturais atinjam os padrões brancos. Sendo assim, participam das principais correntes de vida econômica e social” (Jones, op. cit. p. 143), cujos reflexos são vislumbrados na educação e nos discursos explícitos da raça (Taguieff, 2007).

\section{Resultados e Discussão}

\subsection{As Políticas Multiculturalistas}

Para melhor compreensão dos processos das políticas de combate ao racismo na educação na América Latina, faz-se necessário discutir os aspectos relacionados à recepção das políticas multiculturalistas na região, bem como essas são acolhidas perante os sistemas de ensino da América Latina.

Nesse prisma, a adoção dos princípios multiculturalistas inicia-se pela discussão entre "liberais" e "comunitaristas", 
cujos pontos de divergência seriam as "relações do indivíduo com a cultura a que pertencem, e a posição que o Estado deveria ter perante a diversidade cultural" (Frederico, 2016, p. 240).

Ou seja, os "liberais" enfatizam o indivíduo, podendo observá-lo pelo universalismo como modelo priorizante; não pairando qualquer reconhecimento da diferença, ou de uma identidade cultural. Logo, é individualista. Dessa forma, esses defendem a liberdade para realizar suas escolhas, atribuindo-lhes a regra da neutralidade do Estado.

Em sentido contrário, os "comunitaristas" reconhecem a diversidade. Dessa forma, os indivíduos integram uma coletividade de pertencimento; nesse sentido, compreendem o Estado como "órgão capaz de implementar políticas públicas", cuja proteção cultural tem importância na sua manutenção (Frederico, idem).

Entretanto, segundo Wieviorka (2001) o protagonismo e a adoção no cenário internacional de forma perene de políticas multiculturais devem-se as iniciativas de Charles Taylor e Will Kymlicka, inicialmente, Taylor (1998) ao propor a política de reconhecimento e o direito à diferença das minorias por meio do reconhecimento e identidade:

A exigência de reconhecimento nestes últimos casos adquire uma certa premência devido à suposta relação entre o reconhecimento e identidade, significando este último termo qualquer coisa como a maneira como uma pessoa se define, como é que as suas características fundamentais fazem dela um ser humano (Taylor, 1998, p. 45)

Taylor (1998) discorre sobre o desaparecimento das hierarquias sociais baseadas na noção de honra, que foram (hierarquias) substituídas pela noção moderna de dignidade. Dessa forma, a democracia introduziria a política de reconhecimento igualitário e estatutário para diversas culturas; convertendo-se no "único compatível com uma sociedade moderna" (Taylor, idem, p. 47).

Conforme Andrade (2013), as políticas de diferença propostas por Taylor são tomadas como questões centrais no reconhecimento - condição fundamental para a concretização da identidade -, todavia, inadequadamente realizadas, impactariam, de "forma cruel, subjugando-as através de um sentimento incapacitante de ódio contra elas mesmas" (Taylor, idem, p. 46).

Nesse caso, o reconhecimento igualitário proposto por Taylor dar-se-ia pela noção de autenticidade. Surge a moral como algo importante, pelo fato de delinear o comportamento correto, e as diferenças humanas deveriam assumir sua importância. O ideal de autenticidade passou a existir em razão da diferença e do "declínio da sociedade hierárquica" (Taylor, ibidem, p. 52).

Notadamente, para Taylor, a identidade é assumida a partir das linguagens humanas, quando definimos nossas identidades por meio de todas as suas formas de expressão, atribuindo-lhes significado em relação ao "ambiente no qual os nossos gostos, desejos, opiniões e aspirações fazem sentido" (Taylor, ibidem, p. 54). Logo, a importância do reconhecimento, pela identidade, depende das relações, e decorre das interações com os outros.

Portanto, Taylor buscou demonstrar a política de reconhecimento, a qual estaria vinculada a noção de identidade do indivíduo com uma cultura. Dessa forma, o multiculturalismo passa pelas políticas de reconhecimento, as quais serviram de aporte para o debate desenvolvido no campo da educação e do combate ao racismo:

O principal alvo das atenções deste debate é o mundo da educação, no sentido lato. Um ponto central importante são os departamentos de estudos humanísticos das universidades, onde se fazem exigência para se alterar, alargar ou abandonar o "cânone" dos autores-referência, sobre o pretexto de que o que existe, hoje, é constituído preferencialmente, e na sua quase totalidade, por "homens brancos, falecidos". Dever-se-ia dar mais espaços as mulheres e aos autores de origens e culturas não europeias. Um segundo ponto central diz respeito às escolas do ensino secundário, onde está a tentar, por exemplo, elaborar cursos centrados na cultura africana para escolas onde os alunos são maioritariamente negros (Taylor, ibidem, p. 86). 
Esse fato tem relação com a indicação da política de reconhecimento, que é embasada no valor da diferença pela identidade; seja pessoal ou coletiva, ou na busca de uma igualdade formal, pela cidadania, no contexto da política (Taylor, ibidem).

Outra importante contribuição para o multiculturalismo encontra-se em Kymlica (2008), ao discorrer sobre a necessidade da recepção das normas do direito internacional para a proteção às minorias, resultando na capacidade de promover a cidadania democrática e o direito da promoção da justiça.

Segundo Kymlicka (2008), trata-se da teoria liberal dos direitos das minorias por razão das questões oriundas da diversidade cultural - características comuns nas sociedades modernas -, bem como a consagração dos direitos, que devem ser contempladas por força da tradição dos direitos humanos em favor das minorias:

El principio básico de que los derechos de las minorías están subordinados a los derechos humanos se encuentra en todos los documentos internacionales sobre las minorías y los derechos indígenas, y es un importante punto en común com las teorías del multiculturalismo liberal (Kymlicka, 2008).

Porém, Kymlick (1995) na obra Cidadania Multicultural estabelece as premissas da diversidade cultural em dois padrões: a primeira, representada pelas minorias nacionais, surgem a partir da incorporação de culturas. Dessa maneira, desfrutam de um autogoverno, e estão inseridas em um Estado mais amplo. O segundo grupo, pela imigração (familiar e individual), a qual a diversidade cultural está representada pelos migrantes, quando formam associações e buscam sua integração com as sociedades da qual fazem parte. Isso com vistas a adequar-se às diferenças culturais.

Consequentemente, surgem Estados Multinacionais com culturas involuntárias ou inseridas; minorias nacionais em razão dos processos de invasão ou colonização; e, voluntárias, culturas diferentes, que formam uma federação, não representando uma identidade nacional comum (Kymlicka, 2003).

Portanto, trata-se da cultura societal responsável pela condução da vida do grupo, que pode ser encontrada na língua, na educação, nos processos de imigração e em todos os locais do cotidiano. Também nos espaços públicos e privados, e que refletem nas instituições e práticas diárias das sociedades modernas.

Segundo Igreja (2005), essa situação consolidou-se em razão da influência do Relatório Mundial Sobre o Desenvolvimento Humano, divulgado pelo Programa das Nações Unidas para o Desenvolvimento (PNUD), no ano de 2004, e que traz à luz o debate da diversidade cultural, a qual norteou a consolidação das políticas multiculturais.

Haas (2011) destaca, no documento de 2004, ao atribuir a importância do multiculturalismo fundamentado em três pilares, como estratégia para o desenvolvimento humano: democracia, crescimento a favor dos pobres e a expansão equitativa das oportunidades sociais. Para tanto, o PNUD 2004 estabelece Políticas Multiculturais adicionais, democracia, no acolhimento das identidades; crescimento a favor dos pobres, com programas especiais; e, oportunidades sociais a grupos excluídos (Pnud, 2004).

O documento defende expressamente a abordagem da política multicultural; "não só é desejável, mas também é viável e necessária" (Pnud, 2004, p. 2). Deve ser explícita com o viés de uma verdadeira "cidadania", cujo objetivo é o de promover a diversidade e o pluralismo. Logo, políticas multiculturais recepcionadas e institucionalizadas no contexto latino-americano (Igreja, 2005; Igreja \& Agudelo, 2014).

No tocante ao campo educacional, a política multicultural originou-se por meio da educação intercultural como mecanismo ideal adotado em favor dos grupos minoritários, ou seja, o tratamento destinava-se, explicitamente, a um conjunto de indivíduos, em razão da diferença, identidade e cidadania (Batellan \& Coomans, 1999).

Conforme Araújo (2009), em razão da globalização "por meio da influência dos organismos internacionais que pressionam a aceitação das 'recomendações"' (p. 57) no período compreendido entre 1989 a 2005, as questões multiculturais, 
desde então, são adotadas como ponto central no sistema internacional, ou seja, período da recepção das normas e convençães internacionais.

Mehedi (1999) infere que, a proposta multicultural na educação, englobaria, de igual modo, a educação antirracista; dar-se-ia pela recepção de normas internacionais, além da necessidade de um sistema eficaz de acompanhamento e controle (social e governamental) em razão da existência de uma sociedade multicultural (Coomans, 1999).

Portanto, o regime de igualdade de tratamento e liberdade estar-se-ia contemplado pelos direitos de minorias, os quais são oriundos da adoção do sistema de proteção global. Isso consoante sua recepção pelos países latino-americanos, mediante multiculturalismo, que concede direito à cidadania amparada nos direitos humanos (Kymlicka, 2011).

Destarte, as aplicações de uma política voltada ao multiculturalismo foram as "estratégias e políticas adotadas para governar ou administrar problemas de diversidade e multiplicidade gerada por sociedades multiculturais" (Hall, 2003, p. 50). Isso se deu desde o reconhecimento e admissão de certos direitos. A recepção de normas verificou-se tão somente por razões culturais (Hall, 2003).

Nesse prisma, o modelo de "multiculturalismo liberal hegemônico permite que cada grupo discriminado tenha seu espaço, e celebre sua identidade/cultura sempre que não questionar as hierarquias etno-raciais do poder da supremacia branca, e deixe o status quo intacto" (Grosfoguel, 2007, p. 32). Nesse contexto, estão inseridas as políticas de reconhecimento na América Latina.

\subsection{Transversalidade das políticas multiculturais}

Para a eficácia das políticas públicas multiculturalistas na América Latina, especialmente no campo da educação para as relações étnico-raciais, necessitavam, para sua consecução, de mecanismos de consolidação do modelo da diversidade; oportunidade em que os diversos governos da região adotaram as políticas de transversalidade e intersetorialidade.

Em relação à transversalidade no contexto histórico, tem como fato gerador a inclusão e atuação do movimento internacional das mulheres, das Organizações Não Governamentais e de grupos sociais desde 1960 até a Conferência de Beijing (1995), quando de forma definitiva a União Europeia fez incluir a perspectiva de gênero na carta de direitos fundamentais (Bugni, 2016; Reinach, 2013; Serra 2005).

Serra (2004), ao definir a gestão transversal, discorre sobre a necessidade de sua efetivação. Isso se opera pela cidadania, especialmente na gestão da diversidade e, para que essa perspectiva seja incorporada à administração pública, devese garantir a participação e cooperação da sociedade, buscando novos desenhos organizacionais.

Entre esses arranjos das organizações, destacam-se três problemas para a prática da gestão transversal: i) excesso de expectativas em relação à realidade constituída; ii) os responsáveis pela política transversal são mecanismos subsidiários da estrutura; iii) difícil identificação, avaliação e gestão.

Porém, argumenta ser a política transversal como pretensão em razão das necessidades políticas e das organizações, bem como em função da complexidade social, na medida em que as exigências e limitações técnicas das organizações necessitam dessas articulações em suas agendas políticas, definindo-a:

La gestión transversal, por tanto, se propone como instrumento organizativo adecuado para incorporar, en el trabajo del conjunto, o de una parte significativa de la organización, el tratamiento de políticas, problemas, puntos de vista, segmentos de población, etc. que reflejan la multidimensional de la realidad, sin eliminar ninguna de las dimensiones ya incorporadas en su trabajo a través de la estructura orgánica básica (Serra, 2004, p. 8)

Logo, a política de transversalidade "associa as práticas de coordenação governamental horizontal à resposta aos limites das estruturas hierárquicas e compartimentalizadas tradicionais, com vistas a lidar com os novos temas emergentes no 
período" (Bugni, 2016, p. 97), cuja identificação é de difícil avaliação.

Segundo Maciel (2017), a transversalidade é a coordenação dos processos dos órgãos setoriais, os quais não afetam a gestão operativa; apenas é o instrumento intraorganizativo que orienta, propõe medidas; geralmente, associados à proteção de direitos que não correspondem aos objetivos específicos da organização (Serra, 2004; Cunill-Grau, 2014).

Por sua vez, a intersetorialidade é atribuída como sinônimo de transversalidade em razão da sua aplicação em políticas sociais; todavia, buscaremos dialogar com o conceito de Cunill-Grau (2014), Bugni (2016), Favarelo e Lota (2016), Junqueira (1997) e Quinhões e Fava (2010), para demonstrar que não se trata de convergência de conceitos, e sim de situações distintas. Porém, pelas semelhanças podem levar ao entendimento igualitário.

Segundo Catharino (2013), as políticas de intersetorialidade nascem na área de saúde com a Declaração de Alma-Ata (1978), em razão da necessidade de articulação junto à sociedade, na atenção primária à saúde. Nesse caso, em razão do “espírito da cooperação técnica, bem como em consonância com a nova ordem econômica internacional” (Declaração, 1978).

Conforme Cunill-Grau (2014), desde os anos de 1980, essas políticas, de igual sorte, são adotadas pelas propostas de parcerias público-privadas, cujas reformas do período tinham por objetivo a contratação e privatização de serviços, com os repasses de atividades do Estado à iniciativa privada, com vistas a garantir a melhor produtividade.

De acordo com Cunill-Grau (2014), além da área de saúde, a área de Educação utiliza-se da mesma preocupação, quando a UNESCO (1990 e 2004) adotou essa perspectiva na América Latina, com enfoque aos direitos sociais, conforme a seguinte definição:

A intersetorialidade é a articulação de saberes e experiências no planejamento, realização e avaliação de ações para alcançar efeito sinérgico em situações complexas visando o desenvolvimento social, superando a exclusão social (Junqueira, 1997, p. 37).

Como se depreende da intersetorialidade, seu principal objetivo é a produção de eficiência, ou seja, redução de gastos do setor público, e possui as seguintes especificidades: primeira, integração entre os setores para busca de soluções; segunda, as diferenças entre os diversos setores da organização, os quais devem resolver problemas sociais de forma conjunta (CunillGrau, 2014; Bugni, 2016).

Logo, a coordenação corresponde à transversalidade, e à intersetorialidade como a integração com a fusão das estruturas para a adoção das políticas de modo integral. Para tanto, a UNESCO (2004), do mesmo modo, tende a combinar as definições como similares. Porém, podemos observar a diferença:

Por otra parte, los términos "coordinar" e "integrar" a menudo usados como sinó- nimos implican una distinción importante: "coordinar" significa "llevar a una acción, movimiento o condición común" y "regular y combinar en una acción armónica", mientras que "integrar" significa "combinar para formar una entidad más completa, armónica o coordinada, con frecuencia agregando u ordenando sus partes o elementos". En el contexto de las políticas y programas de la primera infancia, el objetivo de la coordinación intersectorial es reunir a los diferentes sectores sociales y armonizar sus políticas de cuidado y educación, así como sus sistemas de prestación de servicios con el fin de evitar superposiciones, pero sin llegar al extremo de fusionar las estructuras. Por otra parte, la integración intersectorial implica contar con una sola entidad donde confluya la unidad organizacional o estructural de los diversos sectores (Unesco, idem, p. 26).

Essa definição de integração está configurada na necessidade da consecução dos propósitos perseguidos, ou seja, a intersetorialidade depende do controle governamental, que deve "trabajar junto para resolver un problema que definen y asumen como común" (Cunill-Grau, 2014, p. 19), de modo a produzir a melhoria dos serviços públicos (Bugni, 2016).

Nesse prisma, todas as situações de intersetorialidade devem produzir: colaboração, administração centralizada, convergência, recursos e fundos de compartilhados, consolidação, planos de multiagências com serviços contínuos e pessoal 
em regime de colaboração integral, bem como integração, metas e objetivos comuns, governança e enfoque conjunto (CunillGrau, 2014).

Segundo Cunill-Grau (2014), a intersetorialidade apresenta três condições essenciais para sua existência: i) inclusão no ciclo das políticas públicas pela avaliação, na definição e soluções dos problemas e o accountability; ii) grau de união das organizações para a execução das ações de objetivo comum; iii) alteração das formas das organizações envolvidas pela governança com o fim de conflitos e diferenças.

Concordamos com Bugni (2016), o qual corrobora que, a intersetorialidade não pode ser adotada, em sua totalidade, em qualquer política social. Especialmente naquela, cujos fins econômicos são acentuados. Esse modelo de organização implica a autoridade do órgão central do controle da política, consoante solução de problemas complexos; desde a sua causa fundante, até a sua ausência da responsabilização. (Bugni, 2016; Cunill-Grau, 2014) Divergem dessa forma da transversalidade proposta por Bandeira (2004).

Nesse contexto de políticas de recepção do multiculturalismo, com a adoção de instrumento de transversalidade, por meio de orientação das normas internacionais políticas ou de ordem econômicas, foram institucionalizadas nas políticas de combate ao racismo na América Latina. Ou seja, o mecanismo utilizado pelas políticas antirracistas institucionais é o da coordenação ou da transversalidade.

Isso significa o engredamento das forças socioinstitucionais para a construção da agenda governamental. Assim, subsidiar determinados atores sociais, sociedade ou governos, entre aqueles com poder de decisão e influência no campo político para a consecução dos objetivos.

Logo, os órgãos de igualdade racial utilizam da transversalidade como instrumento nas instâncias de disputas ideológicas dos Estados. Assim, busca operacionalizar as políticas públicas perante os mecanismos burocráticos da construção das agendas políticas, ou seja, promover a inclusão da temática étnico-racial perante os detentores do poder de decisão. Dessa forma, subsidiar suas razões de escolha políticas com o objetivo de desconstruir o racismo.

Consequentemente, a transversalidade, nas políticas étnico-raciais, está inserida na proposta de agenda governamental. Porém, resvala na avaliação, ou seja, o fato de que todas as políticas precisam de análise da sua efetividade ou eficácia; não se tratando, portanto, de garantir a "eficácia simbólica", a qual Bourdieu (2008) denomina de "sinceridade" para o alcance real no campo da política.

Isso significa que, deve o gestor de políticas étnico-raciais utilizar-se do seu dever-poder, para fazer inferir se essas práticas estão conseguindo suplantar a agenda política. Dessa forma, garantir a inclusão nas políticas governamentais. Porém, revela um problema característico das políticas transversais, cuja "sinceridade" pode refletir na carreira política do gestor, consoante os efeitos positivos ou negativos, os quais representam sua manutenção ou exclusão do poder governamental.

Ademais, a transversalidade tem sua adoção nas políticas focais e governamentais, pois o risco a que está submetida é a demonstração de que há baixa eficácia, quando se procede à avaliação das políticas governamental por meio de seus ciclos, ou anula o processo político das políticas de diversidades. Assim, ao se construir agenda sem critérios de publicização e análises efetivas causa prejuízo aos executores. Logo, a transversalidade não resolve os problemas inerentes às dificuldades de avaliação; apenas acentua o risco em desfavor do gestor, bem como evita a avaliação.

Portanto, a transversalidade das políticas antirracistas, ainda que ao nosso entender devam ser consideradas Políticas de Estado, com a proposta de diálogo da organização estatal, ao diluir o poder de controle governamental sem a participação dos órgãos de igualdade racial, de modo a evitar o seu empoderamento, é a demonstração inequívoca da presença do racismo institucional no Estado, cuja segregação socioespacialestatal da construção da agenda governamental não lhe garante a eficácia social na educação. 


\section{Considerações Finais}

Dessa forma as políticas públicas antirracistas ao defenderem a proposta de inclusão, no ciclo das políticas, por meio da transversalidade, ou seja, na construção da questão pública na agenda institucional. Essa é razão pela qual os órgãos de avaliação não conseguem demonstrar como essa integração proporcionaria a melhoria dos critérios de avaliação do Estado.

Afinal, a transversalidade tem como função basilar tão somente inserir na agenda governamental, e não no processo de avaliação da política pública; motivo por qual ao excluir a política de intersetorialidade significa a não a participação no momento da tomada de decisão dos órgãos de igualdade racial. Logo, esse não tem poder para a tomada da decisão.

Por sua vez no campo educacional, a transversalidade reflete as políticas multiculturalistas adotadas dos mecanismos internacionais, eis que atua na construção da agenda, que é ausente no momento da tomada de decisão e na implementação característica da intersetorialidade.

Por esse motivo, ao negar a participação dos órgãos de promoção da igualdade racial, com ausência de proposta de mudanças de seus operadores reflete no seu esvaziamento como órgão de política de igualdade racial. Nesse caso, necessária a participação obrigatória e permanente em todas as fases do ciclo da política pública. Dessa forma, produzir dados capazes de refletir as políticas de combate ao racismo para promover eficácia social.

Sugere-se o desenvolvimento de pesquisa cujo escopo seja o antirracismo e a reparação, teoria a ser desenvolvida, fundamentada e consolidada, de modo a contribuir para a desconstrução do racismo e das teses racialistas, contrapondo-se a retórica discursiva da inexistência da intencionalidade e causalidade do racismo.

\section{Referências}

Andrade, A. A. (2013). A política de reconhecimento em Charles Taylor. Dissertação Mestrado. Programa de Pós-Graduação em Filosofia da Faculdade Jesuíta de Filosofia e Teologia de Belo Horizonte. http://repositorio.unicamp.br/jspui/handle/REPOSIP/279868

Araújo, V. P. C. (2009). A multiculturalidade nas políticas educacionais e a formação de professores: Brasil e Portugal. Tese (Doutorado em Educação). UFSCar. https://repositorio.ufscar.br/bitstream/handle/ufscar/2209/2246.pdf?sequence=1

Bambirra, V. \& Santos, T. (1988) Brasil: nacionalismo, populismo e ditadura. Cinquenta anos de crise social. In: Gonzalez Casanova, P.. América Latina: história de meio século (1). Editora Universidade de Brasília.

Bandeira, L. (2004). A transversalidade da perspectiva de gênero nas políticas. Comissão Econômica para América Latina e Caribe - CEPAL, Secretaria Especial de Política para as Mulheres.

Barnadas, J. M. (1990). La Iglesia católica en la Hispanoamérica colonial. In.: Bethell, Leslie (Org). História da América Latina: América Latina Colonial: Europa Y América En Los Siglos XVI, XVII, XVIII. Tomo 2. HUROPE.

Batelaan, P. \& Coomans, F. (1995). The International Basis for Intercultural Education Including Anti-Racist And Human Rights Education. International Association for Intercultural Education (IAIE) in co-operation with UNESCO: International Bureau of Education (IBE) and the Council of Europe.

Bodgan, R. \& Biklen, S. K. (2006). Investigação Qualitativa em Educação: uma introdução à teoria e aos métodos. Portugal: Porto Editora.

Bonfim, D. P. (2014). “Não possui fama nem rumor em contrário”: Limpeza de Sangue e Familiares no Santo Ofício da (Bahia - 1681-1750). Dissertação de Mestrado. Universidade Federal Fluminense.

Bourdieu, P. (2008). A Distinção: crítica social do julgamento. Edusp; Zouk.

Bourdieu, P. (2005). O campo econômico. Revista Política e Sociedade (6).

Bourdieu, P. (2008). Razões Críticas: sobre a teoria da ação. Campinas.

Bugni, R. P. (2016). Políticas Públicas para as Mulheres no Brasil: análise da implementação da política de enfrentamento à violência contra as mulheres em âmbito nacional e municipal. Escola de Artes, Ciências e Humanidades da Universidade de São Paulo. Dissertação Mestrado. Universidade de São Paulo. https://www.teses.usp.br/teses/disponiveis/100/100138/tde-29092016-192652/pt-br.php

Cantharino, I. R. (2013). Ações Intersetoriais na Estratégia de Saúde da Família em um Município da Bahia. Dissertação de Mestrado. Universidade Federal da Bahia. https://repositorio.ufba.br/ri/bitstream/ri/15227/1/Disserta\%C3\%A7\%C3\%A3o\%20Ilena\%20Rafaela\%20Cantharino.\%202013.pdf

Carmichael, S. \& Hamilton, C. (1967). Black Power: The Politics of liberation in America. Randon House.

Carneiro, M. L. T. (2005). Preconceito Racial em Portugal e Brasil Colônia: os cristãos-novos e o mito da pureza de sangue. Perspectiva. 
Cashmore, E. (1996). Dicionário de relações étnicas e raciais. Summus.

Costa Neto, A. G. da (2016). A denúncia de Cesáire ao Pensamento Decolonial. Revista Eixo, 5(2), 46-84. HTTP://Revistaeixo.Ifb.Edu.Br/Ind ex.Php/Revistaeixo/Article/View/310

Costa Neto, A. G. da (2015). A desconstrução do racismo através de Monteiro Lobato: uma análise do caso "Caçadas de Pedrinho". Caderno de Letras UFPEL - Revista do Centro de Letras, 25, 15-35. https://periodicos.ufpel.edu.br/ojs2/index.php/cadernodeletras/article/view/7338

Costa Neto, A. G. da (2019). A Educação das Relações Étnico-Raciais no Brasil e Uruguai: a política institucional de combate ao racismo no sistema de avaliação da educação superior. Tese de Doutorado. Universidade de Brasília. https://repositorio.unb.br/handle/10482/37790

Costa Neto, A. G. da (2020). A filosofia Black Power: o método de análise do racismo institucional. Revista Gestão Universitária. http://www.gestaouniversitaria.com.br/artigos/a-filosofia-black-power-o-metodo-de-analise-do-racismo-institucional

Costa Neto, A. G. da (2012). A questão étnico-racial no método hermenêutico: juridicisação e valor de verdade. Revista Educação Pública CECIERJ. https://educacaopublica.cecierj.edu.br/artigos/12/43/a-questatildeo-eacutetnico-racial-no-meacutetodo-hermenecircutico-juridicisaccedilatildeo-e-valor-deverdade

Costa Neto, A. G. da. (2019). O Fundo Patrimonial de Reparação da Escravidão. In.: Melo, Edelamare (Org.). Negro, Quilombola, Religioso de Matriz Africana: preconceito, racismo, intolerância e discriminação nas relações de trabalho, rdução e consumo. RTM.

Costa Neto, A. G. da (2021). O Piso Nacional dos Profissionais da Educação. Brazilian Journal Of Development, 7(1). https://www.brazilianjournals.com/index.php/BRJD/article/view/23982/0

Costa Neto, A. G. da (2021). "Pedrinho's Hunt” and The Deconstruction of Racism. In. A educação dos primórdios ao século XXI: perspectivas, rumos e desafios. Silva, Américo Junior Nunes da Silva (Org.). Atena.

Costa Neto, A. G. da (2017). Políticas Públicas de Combate ao Racismo e as Estratégias Militares: o aproveitamento do êxito. Revista Educação Pública, CECIERJ. https://educacaopublica.cecierj.edu.br/artigos/17/16/polticas-pblicas-de-combate-ao-racismo-e-as-estratgias-militares-o-aproveitamento-do-xito

Cuello, J. I. \& Cassá, R. \& Silié, R. (1988). “50 anos de História Dominicana”. In: Gonzalez Casanova, P.. América Latina: história de meio século (4). Editora Universidade de Brasília.

Cunill-Grau, N. (2014). La intersectorialidad en las nuevas políticas sociales: Un acercamiento analítico-conceptual. Gest. polít. pública, México, 23(1), 546.

Diwan, P. (2007). Raça Pura: uma história da eugenia no Brasil e no mundo. Contexto.

Drescher, S. (2011). Abolição: uma história da escravidão e do antiescravismo. Unesp.

Dupas, G. (2006). O mito do progresso. Unesp.

Elliot, J. (1990). La conquista española y las colonias de América. In.: Bethell, L. (Org). História da América Latina. Edusp.

Fausto, C. (2005). Os índios antes do Brasil. Jorge Zahar.

Figueroa Rego, J. M. V. de (2009). A honra alheia por um fio: os estatutos de limpeza de sangue no espaço de expressão Ibérica (sécs. XVI- XVIII). Universidade do Minho.

Foucault, M. (2010). Em defesa da sociedade. Martins Fontes.

Franco, J. H. (2011). Sangre limpia, sangre española: El debate de los estatutos de limpeza (siglos V-XVII). Cátedra.

Frederico, C. (2016) O multiculturalismo e a dialética do universal e do particular. Estudos Avançados, 30(87), $237-254$.

Glick, T. (2003). Introduçao. In. Recepção do Darwinismo no Brasil. Domingues, H. M. B. \& Sá, M. R \&. Glick, T. (Org.). Fiocruz.

Gorender, J. (1990). A escravidão reabilitada. Ática.

Gorender, J. (2000). Brasil em Preto e Branco: o passado escravista que não passou. SENAC.

Grinberg, K. \& Peabody, S. (2013). Escravidão e liberdade nas Américas. FGV.

Grosfoguel, R. (2016). A estrutura do conhecimento nas universidades ocidentalizadas: racismo/sexismo epistêmico e os quatro genocídios/epistemicídios do longo século XVI. Revista Sociedade e Estado, 31(1), 25-49.

Grosfoguel, R. (2012). El concepto de «racismo» en Michel Foucault y Frantz. Fanon: ¿teorizar desde la zona del ser o desde la zona del no-ser? (16), 79102. Tabula Rasa,

Grosfoguel, R. (2007). Dilemas dos estudos étnicos norte-americanos: multiculturalismo identitário, colonização disciplinar e epistemologias descoloniais. Cienc. Cult, 59(2), 32-35.

Gualtieri, R. C. E. (2003). O evolucionismo na Produção Científica do Museu Nacional do Rio de Janeiro (1876-1915). In. Recepção do Darwinismo no Brasil. Domingues, H. M. B. \& Sá, M. R. \& Glick, T. (Org.). Fiocruz.

Guimaraes, A. S. A. (2009). Racismo e Antirracismo no Brasil. Ed. 34. 
Hall, S. (2003). A questão Multicultural. In: Sovik, L. (Org.). Da Diáspora: Identidades e mediações culturais. UFMG.

Hasembalg, C. (2005). Discriminação e desigualdades do Brasil. IUPERJ.

Hernandez, G. C. (S.D.). Refleciones sobre el positivismo em américa latina (México-argentina s. XIX).

Hofbauer, A. (2006). Uma história de branqueamento ou negro em questão. UNESP.

Holanda, S. B. (1995). Raízes do Brasil. Companhia das Letras.

Hurtado, J. L. (2008). Las ideia positivas em la América Latina del Siglo XIX. Revista Via Iures, 5, 91-102.

Ianni, O. (1988). A questão nacional na América Latina. Estudos Avançados, 2(1).

Igreja, R. L.; Agudelo, C. (2014). Afrodescedentes na América Latina e Caribe: novos caminhos, novas perspectivas em um contexto global multicultural. Revista de Estudos \& Pesquisas sobre as Américas, 8(1), 13-28.

Igrejas, R. F. M. L. (1995). Estado, Diferença Cultural e Políticas Multiculturalistas: Uma comparação entre. Brasil e México. Doutorado. Departamento de Estudos Latinos Americanos, 1995.

Jones, J. (1973). Racismo e preconceito. Universidade de São Paulo, 1973.

Junqueira, L. A. P. (1997). Novas formas de gestão na saúde: descentralização e intersetorialidade. Saude soc., 6(2), 31-46.

Keller, R. B. de B.; Silva, T. E. M. da. (2021). A linguagem como poder simbólico em um contexto de fronteiras: reflexões sobre a educação da língua espanhola. Research, Society and Development, [S. l.], 10(10).

Kymlicka, W. (2008). Los derechos de las minorías en la filosofía política y en el derecho internacional - IUS. Revista del Instituto de Ciencias Jurídicas de Puebla A.C., (22), 46-72.

Le Goff, J. (2006). Uma história do corpo na Idade Média. Civilização Brasileira.

Lima, P. (2011). De libertos a habilitados: interpretações populares dos alvarás anti-escravistas na América portuguesa (1761-1810). Curitiba.

Lotta, G. \& Favareto, A. (2016). Desafios da integração nos novos arranjos institucionais de políticas públicas no Brasil. Revista de Sociologia e Política, $24(57), 49-65$.

Machado, M. (2012). 7 Ensayos de Interpretacionl de la Realidade de nuesta América: Nação Martí e de José Carlos Mariátegui. Universidade de Brasília.

Maciel, H. M. (2015). Transversalidade e intersetorialidade das políticas públicas: desafios da gestão social. Gestão Social E Políticas Públicas. I Encontro Nacional de Ensino e Pesquisa do Campo de Públicas.

Maldonado-Torres, N. (2007). Sobre la colonialidad del ser: contribuciones al desarrollo de un concepto. In: El giro decolonial: refl exiones para una diversidad epistémica más allá del capitalismo global. Castro-Gómez \& Ramón Grosfoguel (Org.). Instituto Pensar.

Mariategui, J. C. (1928). 7 Ensaios de intepretação da realidade peruana. Amauta.

Mehedi, M. (1999). L'Éducation multicultelle et interculturelle et la protection des minorités. Revue Québécoise de droit international.

Mintz, S. (1996). Africa em América Latina: uma reflexão desprevenida. Siglo XXI.

Morse, R. (2000). O Espelho de Próspero. Publicado em Novos Estudos CEBRAP, 22, 185-192.

Moura, C. (2004). Dicionário da Escravidão Negra no Brasil. Universidade de São Paulo.

Nobles, M. (2009). Shades of Citizenship: Race and the Census in Modern Politics. Stanford University Press.

Olival, F. (2004). Rigor e interesses: os estatutos de limpeza de sangue em Portugal. Cadernos de Estudos Sefarditas, 4, 151-182.

Pala. V. S. (2010). Faut-il en finir avec le concept de racisme institutionnel? Regards Sociologiques, 9, 31-47.

Patterson, O. (2008). Escravidão e Morte Social. Universidade de São Paulo.

Pilkington, A. (2008). From Institutional Racism to Community Cohesion: The Changing Nature of Racial Discourse in Britain. Sociological Research, 13(3).

Pinsk, J. (2009). Escravidão no Brasil. Contexto.

Pnud (2004). Programa das Nações Unidades para o Desenvolvimento. Relatório do Desenvolvimento Humano 2004. Liberdade Cultural num Mundo Diversificado.

Quinhões, T. A. \& Fava, V. M. D. (2010). Intersetorialidade e transversalidade: a estratégia dos programas complementares do bolsa família. Revista do Serviço Público Brasília 61, 67-96.

Reinach, S. (2013). Gestão Transversal das Políticas Públicas no âmbito federal brasileiro: uma leitura inicial. Escola de Administração de Empresas de São Paulo. FGV. 
Ribeiro, D. (1983. As Américas e a Civilização: Formação Histórica e Causas do Desenvolvimento Desigual dos Povos Americanos. Vozes.

Rodrigues, A. C. (2012). Honra e estatutos de limpeza de sangue no Brasil colonial. Revista do instituto cultural judaico marc chagall, 4(1), 75-85.

Rodrigues, P. R. S. (2021). Monteiro Lobato, o “cancelado” de Tabauté: outros significados da denúncia à obra “Caçadas de Pedrinho”. Qualificação de doutorado. Universidades Federal de São Carlos.

Salmoral, M. L. (2000). Les Codes Noirs hispaniques. Unesco.

Serra, A. (2005). La gestión transversal: expectativas y resultados. IX Congresso Internacional do CLAD Sobre a Reforma do Estado e da Administração Pública, revista del CLAD Reforma y Democracia (32), Caracas.

Sicroff, A. (1982). El Lumen ad revelationem gentium, de Alonso de Oropesa, como precursor del erasmismo en España. Autores: Actas del cuarto Congreso Internacional de Hispanistas, 2, 655-664.

Silva, A. M. (1990). Portugal y Brasil: la reorganización imperial, 1750-1808. In.: Bethell, Leslie (Org). História da América Latina: américa latina colonial: europa y américa en los siglos xvi, xvii, xviii. Tomo 2, Hurope, 150-164.

Silva, R. A. R.; Correia, D. B.; Amaro, B. B. D. F.; Silva, M. S. A. da; Queiroz, M. B.; Lima, L. A. de; Vitor, L. N. A.; Santos, R. H. L. dos; Verçosa, C. J.; Figueroa, M. E. V.; Cabral, C. da P.; Santos, M. A. F. dos; Figueirêdo, F. V.; Oliveira, J. P. C. de; Torres, C. M. G.; Oliveira, E. C. C. de (2021). Cooperative Learning as an active methodology in High School: Perception of students from a public school in the City of Milagres, Ceará. Research, Society and Development, [S. l.], 10(8).

Souza, G. M. B. (2008). Uma Trajetória Racista: O ideal de Pureza de Sangue na Sociedade Ibérica e na América Portuguesa. Politeia: História e Sociedade. $8(1), 83-103$.

Taguief, P. (1997). O Racismo. Piaget.

Taylor, C. (1994). A política de Reconhecimento. In: Taylor, C. et al. Multiculturalismo: examinando a política de reconhecimento. Piaget.

Todorov, T. (1982). “I. Descobrir”. A conquista da América: A questão do outro. Martins Fontes.

Van Dijk, T. A. (2021). Discurso Antirracista no Brasil: da abolição às Ações Afirmativas. Contexto.

Van Dijk, T. A. (2006). Discurso de las elites y racismo institucional. In: Lario, M. (Ed.). Medio de comunicación e inmigración. CAM-Obra Social.

Van Dijk, T. A. (2012). Discurso y contexto: un enfoque sociocognitivo. Gedisa.

Van Dijk, T. A. (2009). Discurso y poder. Gedisa.

Van Dijk, T. A. (2003). Dominación étnica y racismo discursivo em España y América Latina. Gedisa.

Van Dijk, T. A. (2000). El discurso como interacción social. Gedisa.

Van Dijk, T. A. (1998). Ideologia: uma aproximación multidisciplinar. Gedisa.

Van Dijk, T. A. (2012). Racismo e discurso na América Latina. Contexto.

Vannuchi, A. (1999). Cultura brasileira: o que é, como se faz. Loyola.

Watkins, D. (2010). La comparación de maneras de aprender. In. Bray, M. \& Adamson, B. \& Mason, M. Educación comparada: un enfoque y métodos. Grânica.

Wievioerka, M. (2007). O Racismo, uma introdução. Perspectiva.

Kymlicka, W. (1996). Cuidadanía multicultural: Una teoría liberal de los derechos de las minorias. Paidós.

Wolf, E. (2005). Europa y la gente sin história. FCE.

Woortmann, K. (2000). O selvagem e a história. Heródoto e a questão do Outro. Revista de Antropologia, 43(1).

Yin, R. (2016). Pesquisa qualitativa do início ao fim. Penso.

Young, R. (2005). Desejo Colonial. Perspectiva. 